Research Article

\title{
Studying Engineering Characteristics of Asphalt Binder and Mixture Modified by Nanosilica and Estimating Their Correlations
}

\author{
Moein Hasaninia ${ }_{(D)}^{1}$ and Farshad Haddadi $\left.{ }^{2}\right)^{2}$ \\ ${ }^{1}$ Department of Civil Engineering, Iran University of Science and Technology (IUST), Narmak, Tehran, Iran \\ ${ }^{2}$ Department of Civil Engineering, Florida International University (FIU), Miami, FL, USA
}

Correspondence should be addressed to Moein Hasaninia; moinhasani@civileng.iust.ac.ir

Received 13 June 2017; Revised 3 October 2017; Accepted 15 October 2017; Published 7 February 2018

Academic Editor: Peter Majewski

Copyright (c) 2018 Moein Hasaninia and Farshad Haddadi. This is an open access article distributed under the Creative Commons Attribution License, which permits unrestricted use, distribution, and reproduction in any medium, provided the original work is properly cited.

\begin{abstract}
The objective of this research was to investigate rutting and fatigue distresses in asphalt containing 2,4 , 6 , and 8 percent of nanosilica (NC) and to find out the correlation between engineering properties of the modified binder and mixture asphalt. In order to study the effect of $\mathrm{NC}$ on the rutting and fatigue properties of modified binders, the multiple stress creep recovery (MSCR) and linear amplitude sweep (LAS) tests were carried out. The Marshall stability, dynamic creep, and four-point bending beam fatigue tests were used to evaluate performance characteristics of the mixtures. The binder and mixture tests all indicated an improvement of fatigue and rutting resistance using NC as a modifier. Furthermore, some statistical correlations between engineering properties were developed successfully.
\end{abstract}

\section{Introduction}

Binder plays an important role in preventing common distresses associated with asphalt mixture such as fatigue cracking and rutting. For instance, binder with enough adhesion and cohesion can significantly hinder the segregation and separation of aggregates from the pavement surface [1]. In order to improve the behavior of asphalt binder at different temperatures, many types of additives have been used. Among them, nanomaterials have been used by many researchers for their high surface area and capability of creating powerful networks in asphalt binder, culminating to an increase in the mixture's resistance to permanent deformation [2]. Performance characteristics of binders and asphalt mixtures have been affected to some extent due to the addition of nanoparticles such as nanoclay, nanolime, carbon nanofiber, and carbon nanotube $[2,3]$.

The effect of nanoclay as an asphalt binder additive on the mechanical properties of the asphalt mixture demonstrated a considerable increase on rutting resistance and resilient modulus of asphalt concrete (AC) samples. However, the additive has no considerable effect on low-temperature fatigue resistance of the modified sample [4].

Amirkhanian et al. studied the effects of carbon nanoparticles on the performance characteristics of asphalt binder. The viscosity, performance grade (PG), creep and creep recovery, and frequency sweep tests were carried out on modified binder. Experiment results indicate that the addition of the carbon nanoparticle was effective in increasing viscosity, failure temperature, complex modulus and elastic modulus, and as a result, rutting resistance of the binder [5].

Yao et al. used NC as a binder modifier. They added NC to an SBS-modified asphalt in 4 and 6 percent by the weight of the modified base binder. Experiment results showed that the value of viscosity at high temperatures decreased slightly; in fact, at low temperatures, modified binder with NC behaves similar to control binder samples; furthermore, NC improved binder antioxidation characteristics. The rutting and fatigue cracking performance of asphalt binder modified by NC was improved [6].

Among the advantages of $\mathrm{NC}$ are its functional features and low-cost production. NC is one of the new minerals which include potential useful features, such as huge surface 
area, good distribution, high absorption, high stability, and high percentage of purity.

Today, researchers are looking for binder tests that not only could demonstrate the mixture's performance-related characteristics of both modified and unmodified binder but also are easy and quick to conduct. Insufficiency of the performance grade (PG) binder specification as one of the common methods to evaluate binder performance, especially when it is modified or rejuvenated by additives, has been proved by many researchers $[7,8]$. To address this issue and as a way to find a better performance-related test method, the LAS and MSCR tests were introduced to evaluate fatigue and rutting performance of the binder, respectively. The LAS test showed a good correlation with long-term pavement performance (LTPP) field fatigue cracking data [9]. Furthermore, unlike the existing SHRP test method, MSCR captures the nonlinear behavior of rutting phenomenon and correlates fairly well with field rutting data [7].

In this research study, the binder is modified by $2,4,6$, and 8 percent of NC, and two important distresses of asphalt, rutting and fatigue, are evaluated through the LAS, MSCR, 4-point bending beam, and dynamic creep tests. Finally, some correlation between binder and mixture test results was developed successfully.

\section{Materials}

The asphalt binder used in this study was AC-60/70, provided by Pasargad Oil Company, Tehran. The characteristics of the binder are presented in Table 1 . The required aggregates to produce the sample are taken from Asb-Cheran Mine located in Roudehen in the north of Tehran. Rock dust is used as the filler in the production of samples. The characteristics of the aggregates are presented in Table 2 . The gradation of aggregates is according to AASHTO M323 and presented in Table 3 and Figure 1. NC used in this research study has a purity of more than $99 \%$. The maximum diameter of the particles is $10 \mathrm{~nm}$, and the surface area is $600 \mathrm{~m}^{2} / \mathrm{g}$. Its bulk density is less than $0.10 \mathrm{~g} / \mathrm{cm}^{3}$, and the true density is $2.4 \mathrm{~g} / \mathrm{cm}^{3}$.

\section{Sample Preparation}

NC is added to the asphalt binder by $2,4,6$, and 8 percent of the original binder's weight. A high-shear mixing device is used to mix NC and binder with $4000 \mathrm{rpm}$ for 2 hours at $135^{\circ} \mathrm{C}$. The SEM images of the modified binder with 4 percent NC in three magnitudes are shown in Figure 2. Accordingly, particles' diameters are roughly between 50 and 150 nanometer.

The Marshall method was used to determine the stability, flow, and optimum binder of all asphalt samples (ASTM D2726 and ASTM D1559). Percentage of optimum binders obtained were $5.5,5.3,5.2,5$ and 4.9 at mixtures with $0 \%, 2 \%$, $4 \%, 6 \%$ and $8 \%$ of NC content, respectively. The samples were compacted using a Gyratory compactor for the dynamic creep, indirect tensile strength, and resilient modulus tests. Samples used in fatigue tests were originally fabricated as slabs with dimensions of $5 * 30 * 40 \mathrm{~cm}$ using wheel track compactor. All the samples made at optimume binder and $4 \%$ air
TABle 1: Physical properties measured of bitumen.

\begin{tabular}{lcc}
\hline Parameter measured & Test method & Test value \\
\hline Specific gravity at $25^{\circ} \mathrm{C}\left(\mathrm{g} / \mathrm{cm}^{3}\right)$ & AASHTO T228 & 1.01 \\
Penetration at $25^{\circ} \mathrm{C}(0.1 \mathrm{~mm})$ & AASHTO T49 & 60 \\
Softening point $(\mathrm{R} \& \mathrm{~B})\left({ }^{\circ} \mathrm{C}\right)$ & AASHTO T53 & 56 \\
Viscosity at $120^{\circ} \mathrm{C}$ (centistokes) & AASHTO T201 & 1055 \\
Viscosity at $135^{\circ} \mathrm{C}$ (centistokes) & AASHTO T201 & 361 \\
Viscosity at $160^{\circ} \mathrm{C}($ centistokes) & AASHTO T201 & 170 \\
Ductility at $25^{\circ} \mathrm{C}(\mathrm{cm})$ & AASHTO T51 & $>100$ \\
\hline
\end{tabular}

void. Then, they were sawn to the prismatic beams with dimensions of $38.5 \mathrm{~mm} \times 63.5 \mathrm{~mm} \times 50 \mathrm{~mm}$, considering the AASHTO T321 standard [10].

The binder performance characteristic tests have been carried out on aged samples. Prior to the multiple stress creep recovery (MSCR) and linear amplitude sweep (LAS) tests, all the modified binder samples, as well as the 60/70 base binder, were aged in the rolling thin-film oven (RTFO) in order to represent a short-term aging condition.

\section{Experimental Design}

4.1. Multiple Stress Creep Recovery (MSCR). This test has been used to measure the percent of recovered strain $(R)$ and unrecovered strain $\left(j_{\mathrm{nr}}\right)$ of asphalt binders. The elastic response of the binder under the shear stresses can be calculated by this test methodology. The aged samples in the RTFO process are used in this test method. In order to conduct the MSCR test, the dynamic shear rheometer (DSR) is used. The binder sample is put under a $0.1 \mathrm{kPa}$ shear stress for a 1 -second duration, followed by a 9 -second rest period at the temperature of $60^{\circ} \mathrm{C}$. This loading repeats for 10 cycles. Then, after the completion of the first ten cycles, a similar procedure will be applied to the sample with a stress level of $3.2 \mathrm{kPa}$. According to the ASTM D-7405-10a standard, at each $0.1 \mathrm{sec}$ interval, the relevant output should be recorded [11].

4.2. Linear Amplitude Sweep (LAS) Test. This test was proposed by Johnson and Hintz to investigate the fatigue resistance of asphalt binders [12]. According to the AASHTO standard (AASHTO-TP 101-12-UL), the binder samples of $8 \mathrm{~mm}$ thickness are tested in the dynamic shear rheometer (DSR). All DSR tests are conducted on RTFO aged samples. The test is carried out under the strain-controlled mode with linearly increased load amplitudes from $0.1 \%$ to $30 \%$ strain in a total time of 310 seconds [13].

In the viscoelastic continuum damage (VECD) analysis, the binder fatigue performance parameter $N_{f}$ can be calculated by

$$
N_{f}=A_{35} \times \gamma^{B}
$$

where $N_{f}$ is the number of cycles to failure, $A_{35}$ is the damage intensity corresponding to 35 percent reduction of undamaged $\left|G^{*}\right| \sin \delta$, and $B$ demonstrates the binder sensitivity to applied strain level. The parameters $A_{35}$ and $B$ are experimentally defined, and $\gamma$ is the applied shear strain. 
TABle 2: Properties of used aggregates.

\begin{tabular}{|c|c|c|c|}
\hline Properties & Method & Requirement & Values \\
\hline \multicolumn{4}{|l|}{ Coarse aggregate } \\
\hline Los Angeles abrasion (\%) & AASHTO T96 & 30 max. & 20 \\
\hline Water absorption (\%) & AASHTO T85 & 5 max. & 0.8 \\
\hline Bulk specific density $\left(\mathrm{g} / \mathrm{cm}^{3}\right)$ & AASHTO T85 & - & 2.654 \\
\hline Flat and elongated (3-1) (\%) & ASTM D4791 & $20 \max$. & 12 \\
\hline Soundness (sodium sulfate) (\%) & AASHTO T104 & $15 \max$. & 4.8 \\
\hline Crushed content (one face) (\%) & ASTM D5821 & $100 \mathrm{~min}$. & 100 \\
\hline Crushed content (two faces) & ASTM D5821 & $90 \mathrm{~min}$. & 100 \\
\hline \multicolumn{4}{|l|}{ Fine aggregate } \\
\hline Water absorption (\%) & AASHTO T84 & - & 1.4 \\
\hline Bulk specific density $\left(\mathrm{g} / \mathrm{cm}^{3}\right)$ & AASHTO T84 & - & 2.617 \\
\hline \multicolumn{4}{|l|}{ Mineral filler } \\
\hline Bulk specific density $\left(\mathrm{g} / \mathrm{cm}^{3}\right)$ & AASHTO T84 & - & 2.702 \\
\hline
\end{tabular}

TABLE 3: Gradation of the aggregates used in the study.

\begin{tabular}{lccccccc}
\hline Sieve sizes & US & $3 / 4^{\prime \prime}$ & $1 / 2^{\prime \prime}$ & No. 4 & No. 8 & No. 50 & No. 200 \\
\hline Sieve sizes & Metric & 19 & 12.50 & 4.75 & 2.36 & 0.3 & 0.075 \\
Passing (\%) & HMA gradation & 100 & 95 & 60 & 40 & 15 & 5 \\
\hline
\end{tabular}

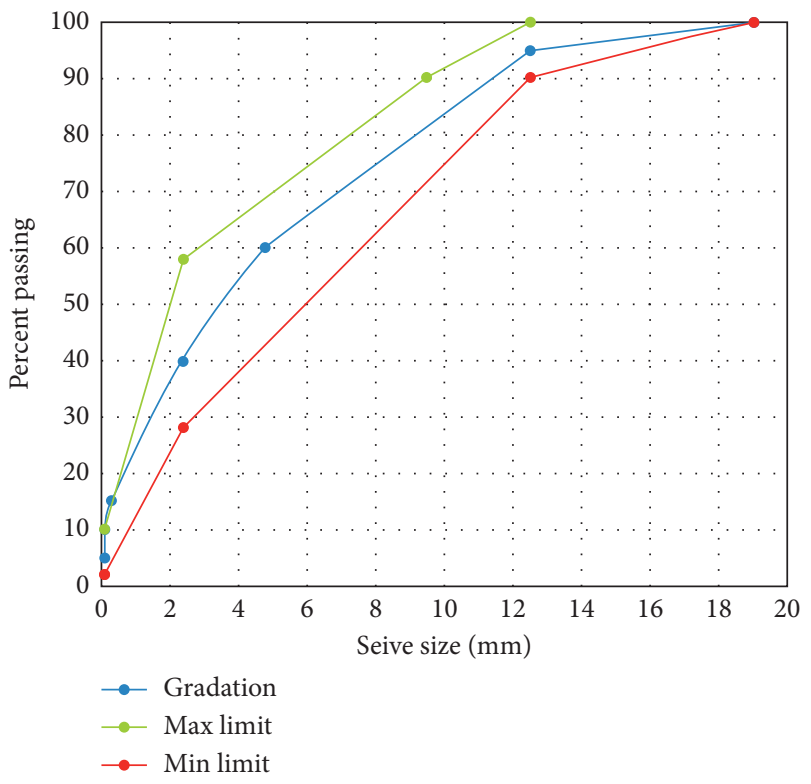

FiguRE 1: Gradation of designated aggregates.

4.3. Marshall Stability and Quotient. The test was carried out according to ASTM D1559. Before the test, all samples were put in $60^{\circ} \mathrm{C}$ water for 30 minutes. Marshall stability is the peak resistance load obtained during a constant rate of the deformation load sequence, and Marshall flow is a measure of deformation of the asphalt mix determined during the stability test. The Marshall quotient equals the ratio of the Marshall stability to the value of the Marshall flow. The value of the Marshall quotient indicates the resistance of asphalt mixtures against permanent deformations and the value of rutting [14].
4.4. Resilient Modulus. Resilient modulus is one of the important parameters in the pavement design procedure. The measurement of this parameter is in the form of pavement response under dynamic loads and the corresponding strains associated with them. The value of resilient modulus is measured based on the ASTM D4123 [15] standard. This test is conducted at temperatures of $5^{\circ} \mathrm{C}$ and $25^{\circ} \mathrm{C}$, and the minimum numbers of loadings are 100 . The value of resilient modulus $\left(M_{r}\right)$ can be obtained by [16]

$$
M_{r}=P \frac{(\mu+0.27)}{\left(t \delta_{h}\right)}
$$

where $P$ is the maximum dynamic load $(\mathrm{N}), \mu$ is Poisson's ratio, $t$ is the specimen length $(\mathrm{mm})$, and $\delta_{h}$ is the horizontal recoverable deformation $(\mathrm{mm})$.

4.5. Dynamic Creep Test. In the present research, the dynamic creeping test has been used to evaluate the rutting property of the asphalt mixtures. The output creep curve of the test is made of three areas. In the present article, the flow number $\left(F_{n}\right)$ parameter is used as representation of rutting resistance of asphalt mixtures, which is the number of cycles the creep curve enters from the second to the third phase [17].

4.6. Four-Point Beam Fatigue Test. The fatigue life of the asphalt mixtures is evaluated by the 4-point bending beam test under AASHTO-T321 standard specifications. A constant sinusoidal loading was applied on beam specimens at constant strain levels of 600,800 , and 1000 microstrains until 50 percent reduction of initial stiffness. 


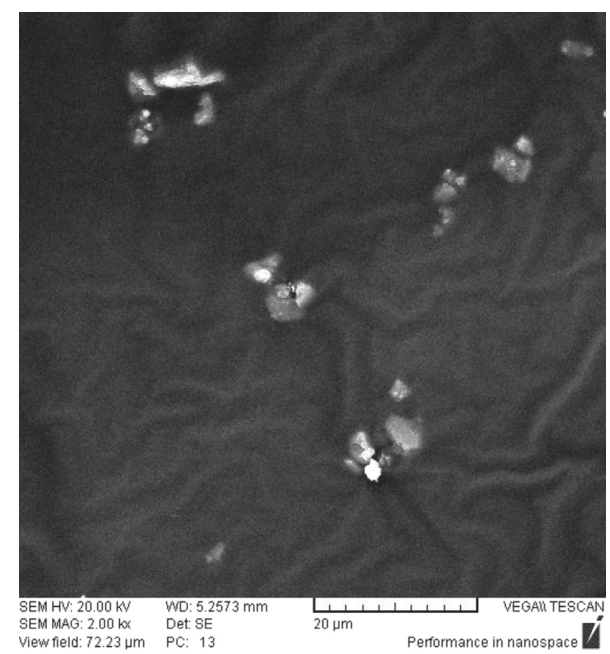

(a)

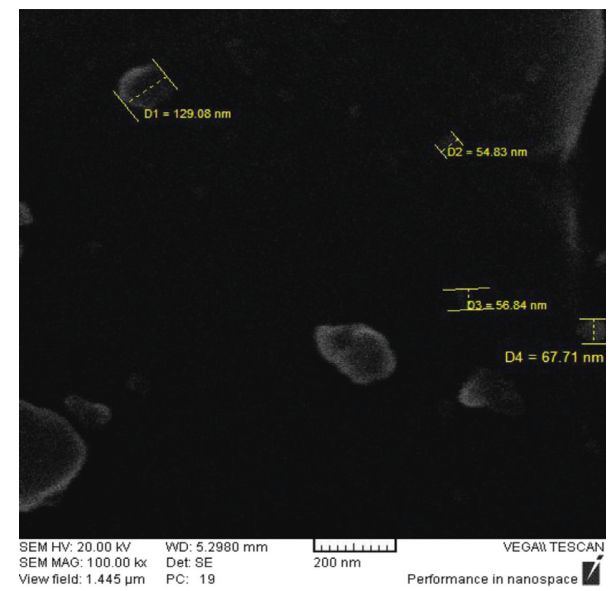

(b)

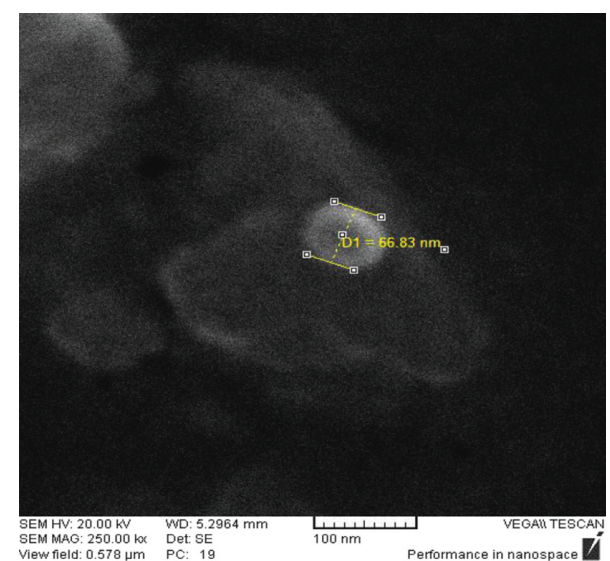

(c)

FIGURE 2: SEM images of NC with asphalt binder: (a) $20 \mu \mathrm{m}$, (b) $200 \mathrm{~nm}$, and (c) $100 \mathrm{~nm}$.

\section{Results and Discussion}

\subsection{Binder Test}

5.1.1. MSCR Test Results. The MSCR test encompasses different outputs. The accumulated strain versus time over

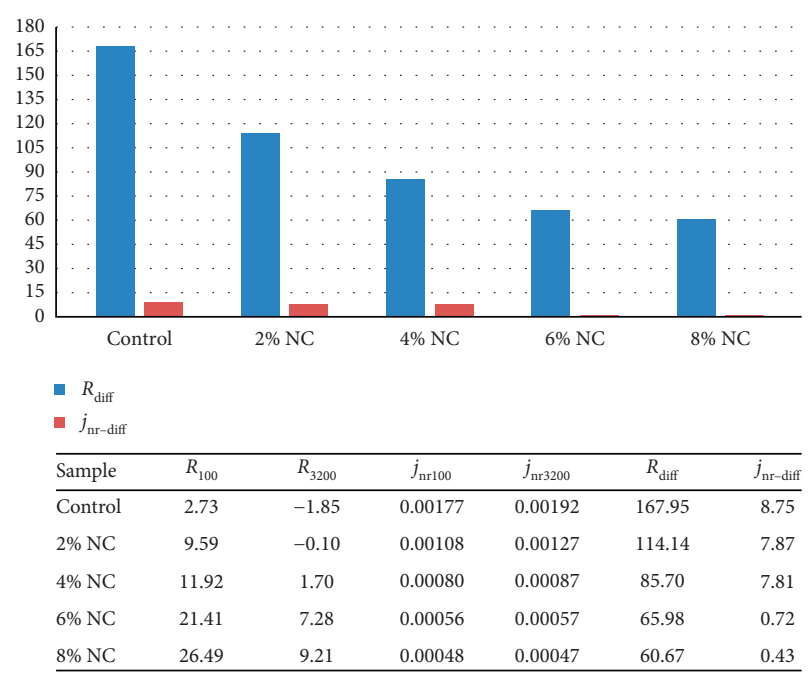

FIGURE 3: Summary of MSCR test results.

a 10 -cycle period for the shear stress values of $100 \mathrm{~Pa}$ and $3200 \mathrm{~Pa}$ is shown in Figure 3. Results indicate a considerable decrease in accumulated strain for the NC-modified binders. An amount of $8 \%$ of $\mathrm{NC}$ decreases the accumulated strain of the base binder from $1.7 \%$ to $0.4 \%$ over a 10 -cycle period under a $100 \mathrm{~Pa}$ shear stress. For the case of $3200 \mathrm{~Pa}$ applied shear load, the accumulated strain decreased from $62 \%$ to $14 \%$. This decrease indicates a higher resistance of the modified binders against applied stresses and consequently decreases of binder deformation under cyclic loading.

The values of percent recovered strain $(R)$ for base and modified binders are also shown in Figure 3. It can be seen that, by adding NC, there is a considerable increase in recovered strain in the modified binders. Under a $100 \mathrm{~Pa}$ load, the recovered strain for base and modified binders with $8 \%$ of NC is 2.73 and 26.94, respectively. The recovered strain under $3200 \mathrm{~Pa}$ shear stress for the modified binder containing $8 \%$ of $\mathrm{NC}$ is 9.21 , while the value for the base binder is less than zero. This negative $R$ value is due to the fact that the binder has no recovered strain during the unloading process. Since any increase in percent recovered strain contributes to an increase in elastic response of the binder, adding NC causes an increase in recovered strain of the binder and improves the elastic response of it.

The permanent deformation characteristics of binders can be quantified by the $j_{\mathrm{nr}}$ parameter. A less value of $j_{\mathrm{nr}}$ indicates lower permanent deformation of the binder. The $j_{\mathrm{nr}}$ values under the $100 \mathrm{~Pa}$ and $3200 \mathrm{~Pa}$ shear loads for all base and modified binders are shown in Figure 3. It can be seen that adding $\mathrm{NC}$ can decrease the $j_{\mathrm{nr}}$ values, and as a result, the permanent deformation of the modified binders decreased. The stress sensitivity of the binder can be described by the $j_{\text {nr-diff }}$ and $R_{\text {diff }}$ values. The less $j_{\text {nr-diff }}$ and $R_{\text {diff }}$ values indicate less stress sensitivity, and the binder has similar behavior under the $100 \mathrm{~Pa}$ and $3200 \mathrm{~Pa}$ shear loads. The $j_{\text {nr-diff }}$ and $R_{\text {diff }}$ values are also shown in Figure 3 . The results indicate a considerable decrease in the $j_{\text {nr-diff }}$ and $R_{\text {diff }}$ values. Therefore, adding NC can decrease the stress sensitivity of the binder. 
TABLE 4: Linear amplitude sweep (LAS) test results.

\begin{tabular}{lccccc}
\hline Parameters & $0 \% \mathrm{NC}$ & $2 \% \mathrm{NC}$ & $4 \% \mathrm{NC}$ & $6 \% \mathrm{NC}$ & $8 \% \mathrm{NC}$ \\
\hline$A_{35}$ & 33,200 & 49,334 & 57,990 & 134,765 & 146,928 \\
$B$ & -1.92 & -2.09 & -2.13 & -2.35 & -2.45 \\
\hline
\end{tabular}

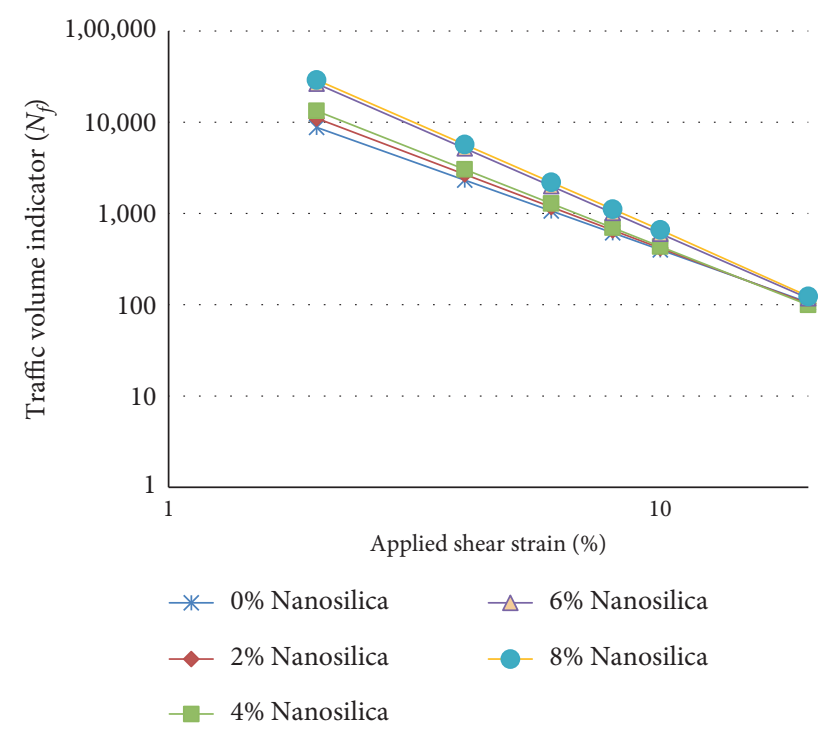

FIGURE 4: Fatigue models from the VECD analysis.

5.1.2. LAS Test Results. The results of linear amplitude sweep (LAS) tests are analyzed based on the theory of viscoelastic continuum damage. Utilizing this theory, $A_{35}$ and $B$ parameters should be calculated to assess the fatigue life of the asphalt binder. A higher value of $A_{35}$ indicates better performance of the binder. Results showed that modified binders with NC had higher $A_{35}$. The $A_{35}$ values for unmodified and modified binders are presented in Table 4 .

The increase in the absolute value of $B$ indicates that, by increasing the level of strain, the fatigue life will decrease in a higher rate. Moreover, any decrease in the absolute value of the parameter $B$ indicates the reduction in the rate of fatigue life. The $B$ values for unmodified and modified binders are presented in Table 4. Results show that adding $\mathrm{NC}$ can increase the binder sensitivity against loading level strain.

The trend of fatigue life of asphalt binders based on the VECD theory is depicted in Figure 4. Values in the $Y$-axis are the number of cycles to failure $\left(N_{f}\right)$, which are indicative of traffic loads passing on the pavement, and the $X$-axis demonstrates applied shear strain. Results show that adding $\mathrm{NC}$ causes an increase in $N_{f}$ values for lower shear strain levels. The $N_{f}$ values for modified binders with 6 and 8 percent of NC are almost identical at low shear strain levels.

\subsection{Mixture Performance Analysis}

5.2.1. Marshall Stability, Flow, and Quotient Tests. Table 5 summarizes the engineering properties of the mixtures. The maximum increase of the Marshall stability, flow, and quotient is for the mixtures containing $8 \%$ of NC, which are improved by $31 \%, 12 \%$, and $35 \%$, respectively. The more the amount of Marshall quotient, the stronger the asphalt mixture is against permanent deformation [14].

5.2.2. Resilient Modulus Test. Resilient modulus $\left(M_{r}\right)$ is an important factor in designing the pavement. Results of $M_{r}$ show that, at $25^{\circ} \mathrm{C}$ temperature, the $M_{r}$ value is 1.37 times greater than the base binder when the NC content is $8 \%$, and at $5^{\circ} \mathrm{C}$ temperature, the $M_{r}$ value is 1.24 greater than the unmodified binder when the NC content is $8 \%$. Accordingly, $\mathrm{NC}$ improved fatigue resistance. Other research test results on polymer-modified asphalt showed that adding NC increases fatigue resistance at intermediate temperatures conducting the same test [18].

5.2.3. Dynamic Creep Test. Dynamic creep test results indicate that asphalt mixtures modified with $\mathrm{NC}$ have higher resistance against permanent deformation in comparison to control samples. Such an increase in NC can raise the flow number, which is a parameter of resistance against rutting. Increasing the amount of NC by $8 \%$ led to an almost $71 \%$ increase in the flow number. This finding is in a good agreement with other researchers $[6,18]$.

5.2.4. Four-Point Beam Fatigue Test. In the 4-point bending beam test, it was observed that, by increasing the percentage of NC, the variation trend of $N_{f}$ in all three strain levels identically increased. Adding $8 \%$ of NC to the base binder increased the fatigue life of asphalt mixtures to the amount of $52 \%, 92 \%$, and $65 \%$ under 600,800 , and 1000 microstrains, respectively.

Further details and discussions about engineering performance of NC-modified mixture are presented in another article by the same authors [19].

5.3. Regression Analysis. A series of linear regression models between binder test results, which are considered as independent, and mixture test results, which are considered as dependent, are developed. Linear regression is a statistical method that defines the relationship between two independent variables [20]. Summary of $R$-squared values and equations for each correlation is presented in Table 6. Independent values did not have strong correlation with each other, so it was possible to develop a reliable regression model and avoid the multicollinearity problem. Examples of two correlations of three independent variables are shown in Figure 5. On the other hand, the independent and dependent variables showed strong correlations with $R$-squared values close to 1 . Furthermore, for each correlation, there is a fundamental relation between independent and dependent variables, which makes them comparable. For example, Nf and A35 correlation is investigated because both represent the fatigue performance; one for mixture and the other for binder. So, the same characteristics are correlated to see if it is possible to estimate one using the other. Also, MSCR test results are proved to have a good correlation with the rutting depth obtained from the field 
TABle 5: Summary of mixture test outcomes.

\begin{tabular}{|c|c|c|c|c|c|c|}
\hline & & Control & Mixture $+2 \%$ NC & Mixture $+4 \%$ NC & Mixture $+6 \%$ NC & Mixture $+8 \%$ NC \\
\hline Average Marshall stability (KN) & - & 10.23 & 11.30 & 12.10 & 12.73 & 13.40 \\
\hline Average Marshall flow (mm) & - & 4.2 & 4.32 & 4.41 & 4.55 & 4.72 \\
\hline MQ $(\mathrm{KN} / \mathrm{mm})$ & - & 2.44 & 2.62 & 2.74 & 2.80 & 2.84 \\
\hline$N_{f}$ (4-point bending beam) & $\begin{array}{c}@ 600 \mu \varepsilon \\
@ 800 \mu \varepsilon \\
@ 1000 \mu \varepsilon\end{array}$ & $\begin{array}{c}106,092 \\
76,738 \\
26,246\end{array}$ & $\begin{array}{c}120,477 \\
85,541 \\
33,888\end{array}$ & $\begin{array}{c}141,428 \\
113,843 \\
38,133\end{array}$ & $\begin{array}{c}151,623 \\
139,781 \\
42,355\end{array}$ & $\begin{array}{c}158,685 \\
147,428 \\
43,414\end{array}$ \\
\hline Resilient modulus & $\begin{array}{l}@ 25^{\circ} \mathrm{C} \\
@ 5^{\circ} \mathrm{C}\end{array}$ & $\begin{array}{c}3520.2 \\
11,884.6\end{array}$ & $\begin{array}{c}3707.5 \\
12,826.2\end{array}$ & $\begin{array}{c}3976.2 \\
13,255.3\end{array}$ & $\begin{array}{c}4420.6 \\
13,988.7\end{array}$ & $\begin{array}{c}4828.5 \\
14,711.5\end{array}$ \\
\hline
\end{tabular}

TABLE 6: Summary of correlation equations and regression coefficients.

\begin{tabular}{lccc}
\hline $\begin{array}{l}\text { Dependent } \\
\text { variable }(y)\end{array}$ & $\begin{array}{c}\text { Independent } \\
\text { variable }(x)\end{array}$ & Equation & $R^{2}$ \\
\hline$N_{f} @ 600$ & $A_{35}$ & $y=0.3763 x+103,883$ & 0.8097 \\
$N_{f} @ 800$ & $A_{35}$ & $y=0.5729 x+64,290$ & 0.9086 \\
$N_{f} @ 1000$ & $A_{35}$ & $y=0.1008 x+29,046$ & 0.8712 \\
& & $y=-85,5191 x$ & 0.9626 \\
Dynamic creep & $j_{\mathrm{nr} 100}$ & +3066.6 \\
Dynamic creep & $j_{\mathrm{nr} 3200}$ & $y=-760,429 x+3040$ & 0.9829 \\
Marshall & $j_{\mathrm{nr} 100}$ & $y=-309.13 x+2.978$ & 0.9915 \\
Marshall & $j_{\mathrm{nr} 3200}$ & $y=-272.86 x+2.9663$ & 0.9976 \\
$M_{r}$ at 5 & $R_{100}$ & $y=114.28 x+11,676$ & 0.9816 \\
$M_{r}$ at 20 & $R_{3200}$ & $y=55.483 x+3289.8$ & 0.9755 \\
\hline
\end{tabular}

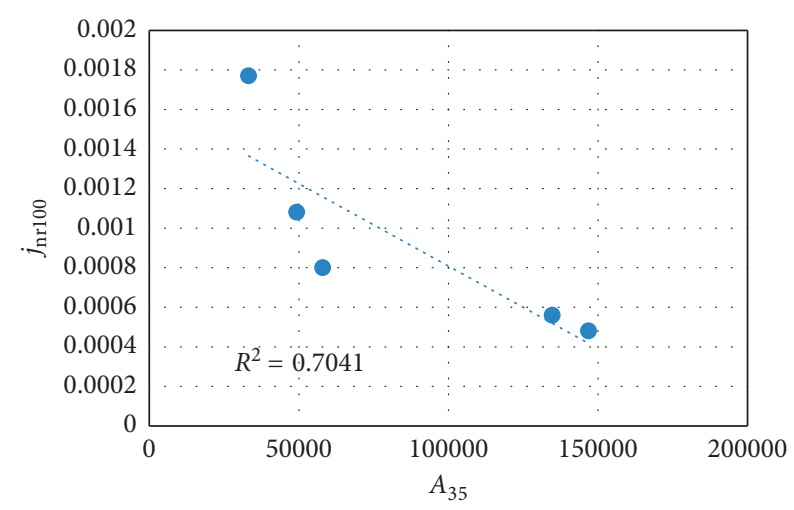

(a)

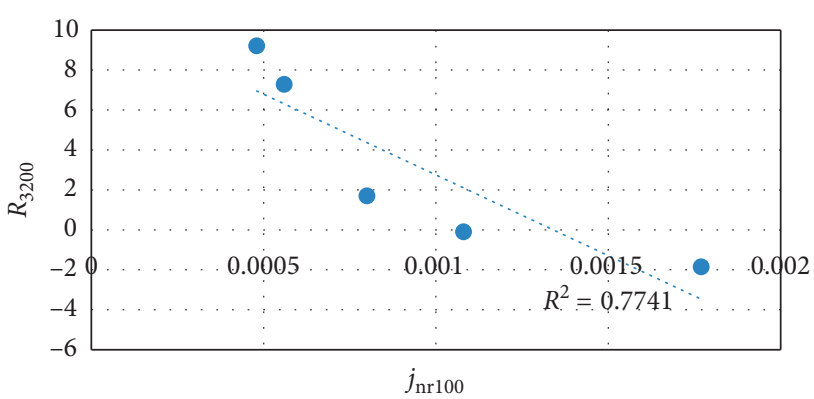

(b)

Figure 5: Correlation between independent vriables (a) A35 vs. Jnr100 and (b) Jnr100 vs. R3200.

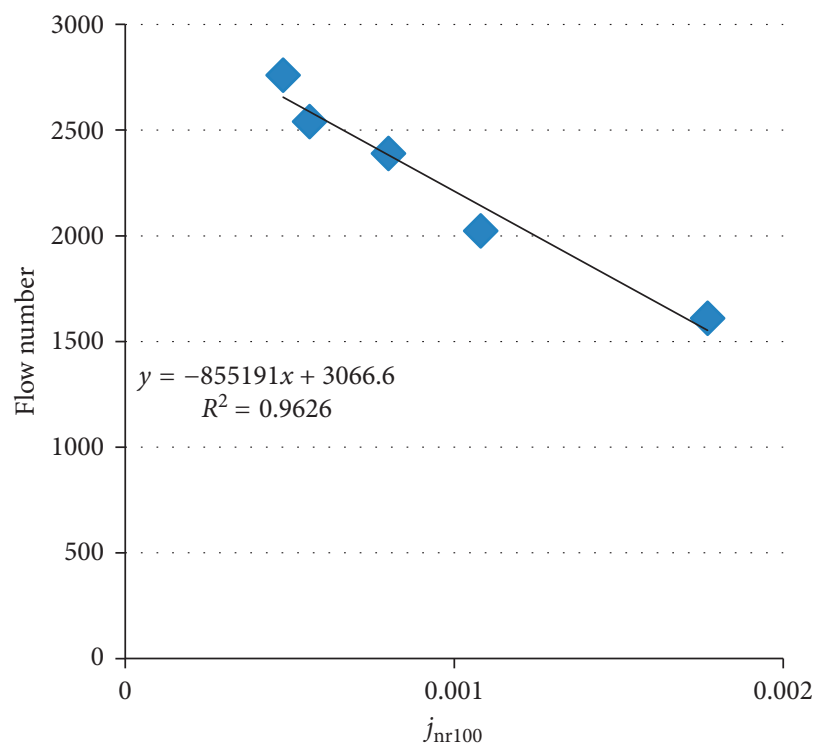

(a)

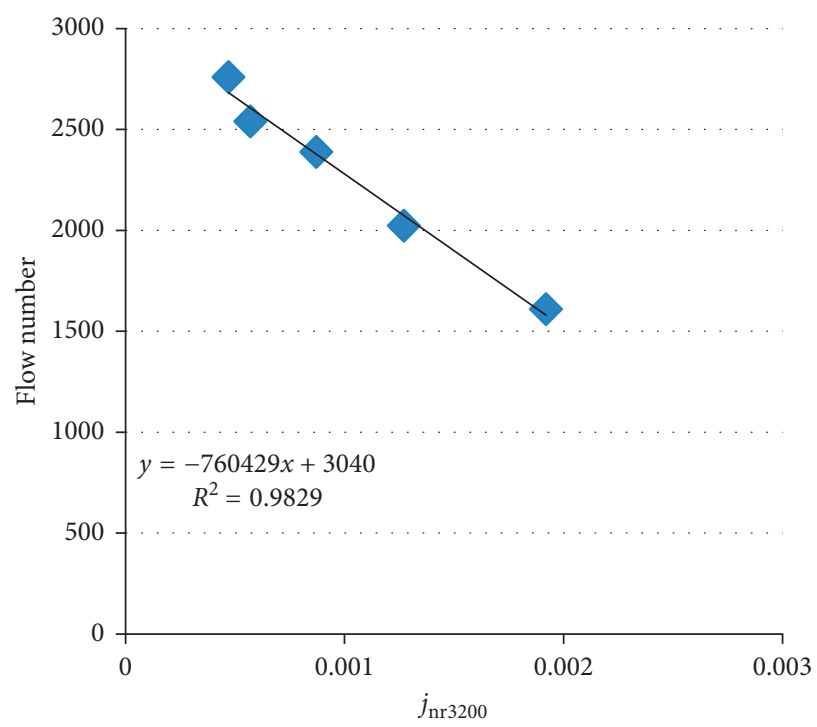

(b)

FigURE 6: Flow number of mixture versus (a) $j_{\mathrm{nr} 100}$ and (b) $j_{\mathrm{nr} 3200}$.

measurements [7]. Therefore, in this research, flow number, $\mathrm{MQ}$, and $M_{r}$ as parameters showing rutting susceptibility of mixture, are also correlated with MSCR test results. 


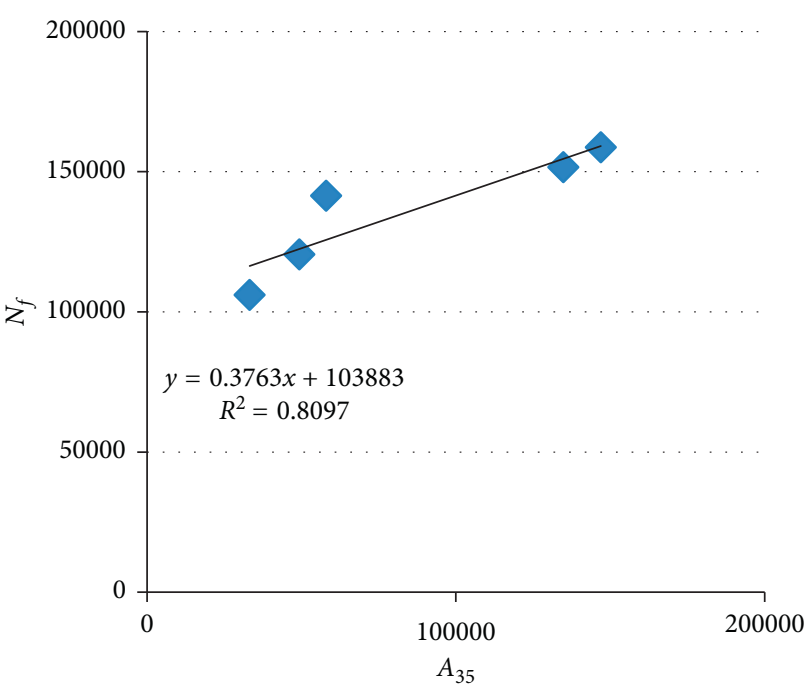

(a)

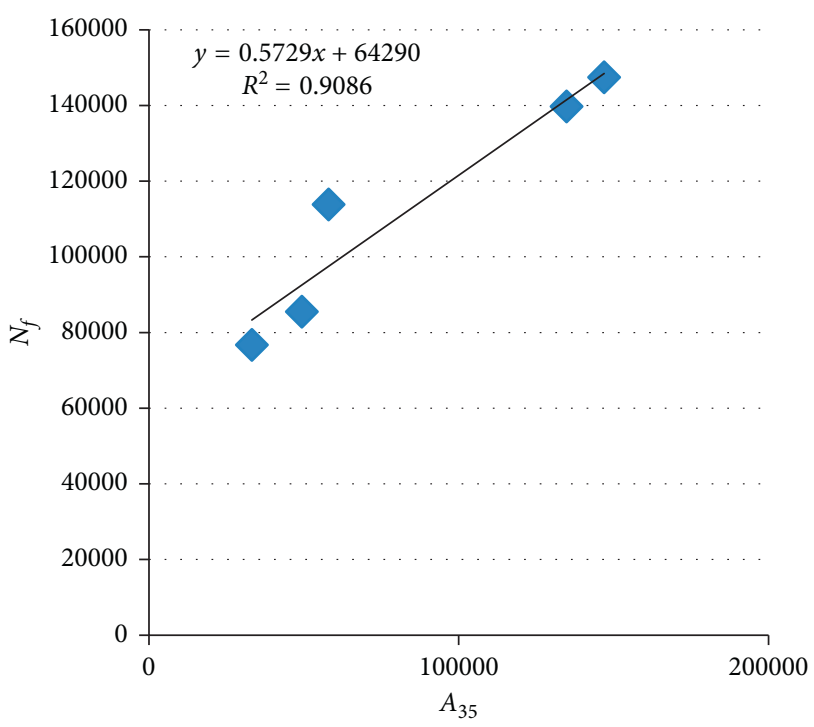

(b)

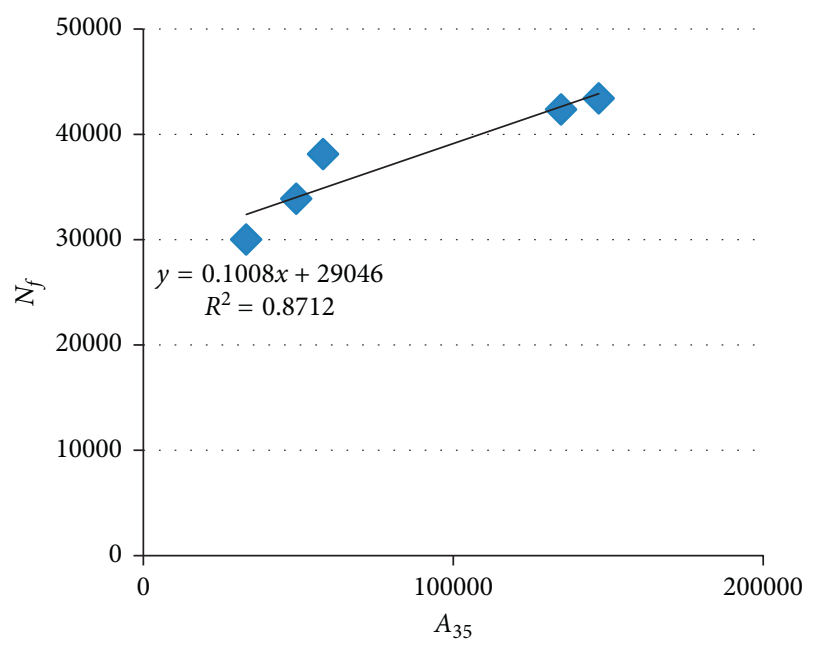

(c)

Figure 7: Fatigue life of mixture $\left(N_{f}\right)$ at three strain levels: (a) $600 \mu \varepsilon$, (b) $800 \mu \varepsilon$, and (c) $1000 \mu \varepsilon$ versus $A_{35}$.

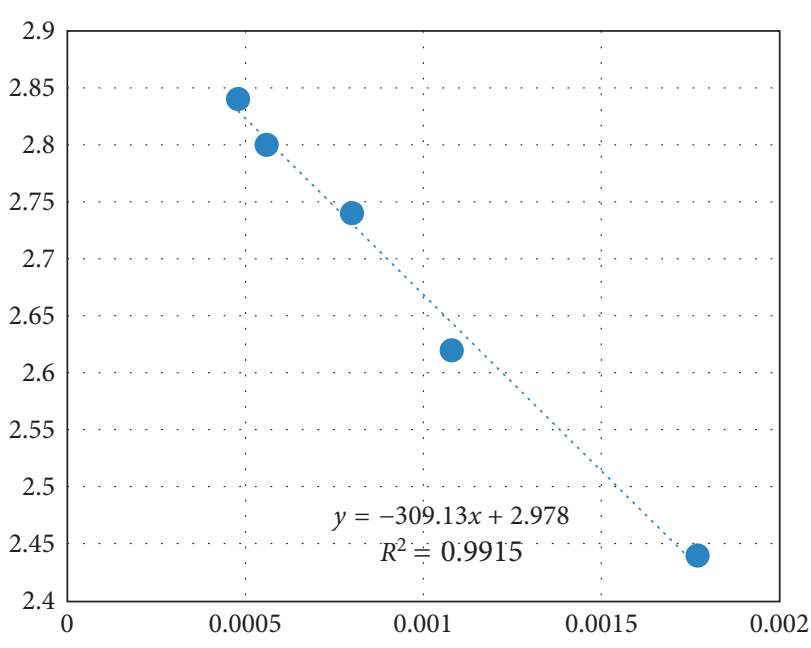

(a)

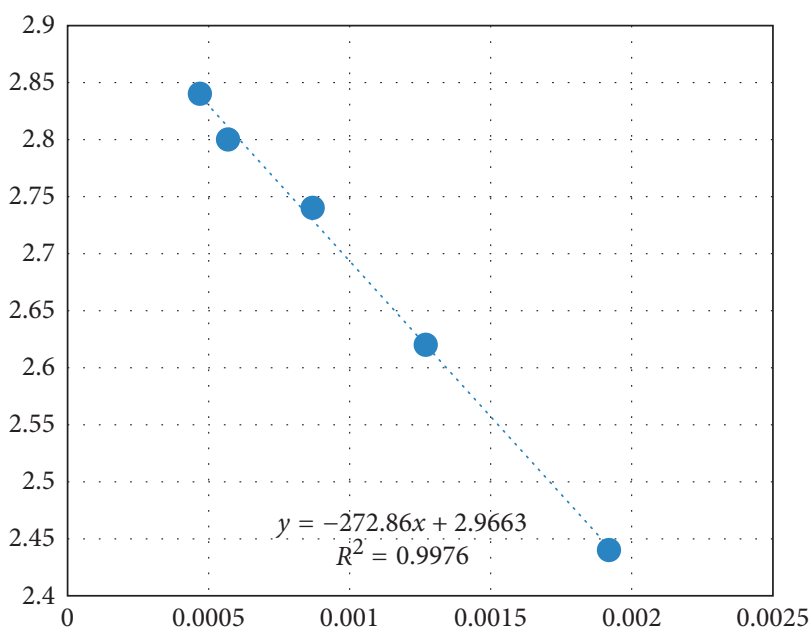

(b)

Figure 8: Marshall quotient versus (a) $j_{\mathrm{nr} 100}$ and (b) $j_{\mathrm{nr} 3200}$.

5.4. Correlation between Flow Number and $j_{\mathrm{nr}}$. Results of the flow number of mixture versus nonrecoverable compliance $\left(j_{\mathrm{nr}}\right)$ are depicted in Figure 6. It is observed that flow number and $j_{\mathrm{nr}}$ are inversely correlated, showing a good correlation ( $R^{2}$ more than 0.9). This indicates that the MSCR binder test result has a close relation with the mixture's response, and using its data could give us a good estimation of the mixture's performance.

5.5. Correlation between $A_{35}$ of LAS Test and Mixture $N_{f}$. Fatigue properties of the mixture are strongly correlated to those of binders. Therefore, modifying the binder could considerably alter fatigue behavior of the mixture, and the binder test could give us a good estimation of fatigue characteristics of the mixture [21]. In this research, results of the 4-point bending beam and LAS tests were studied in correlation with each other. According to Figure 7, the fatigue life obtained from the 4-point bending beam test is in a fairly well correlation with $N_{f}$ values for the binder test. 


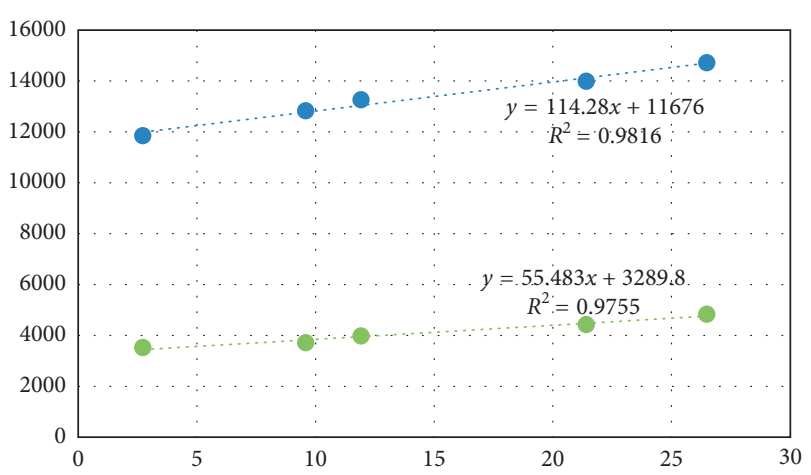

Figure 9: Resilient modulus at $5^{\circ} \mathrm{C}$ and $25^{\circ} \mathrm{C}$ versus $R_{100}$.

$A_{35}$ parameter represents fatigue life of the asphalt binder subjected to a rate of $1 \%$ strain, which is the recommended value by the Superpave. Plotting $A_{35}$ versus fatigue life of asphalt mixture shows a good relation between them. The best correlation was for the strain level of $800 \mu \varepsilon$, and the lowest $R^{2}$ was for the strain level of $1000 \mu \varepsilon$.

5.6. Correlation between Marshall $Q$ and $j_{\mathrm{nr}}$. The Marshall stiffness index (or Marshall quotient) represents the resistance of the material to shear stress and permanent deformation. Higher MQ means the mixture is stiffer and is more resistant against rutting. The permanent deformation characteristics of binders are quantified by the $j_{\mathrm{nr}}$ parameter. The lower value of $j_{\text {nr }}$ indicates lower permanent deformation of the binder. Thus, the MQ correlation with unrecovered $j_{\text {nr }}$ parameter makes sense as both are indicators of resistance against permanent deformation. As shown in Figure 8, it was observed that the MQ is inversely correlated with $j_{\mathrm{nr}}$. This indicates that as the MQ increases, the unrecovered strain of the binder decreases, which means less susceptibility to rutting. $R^{2}$ is too close to 1 for five samples, which is a promising result so as to find the mixture performance using easier and faster binder tests.

5.7. Correlation between $M_{r}$ and $R_{100}$. Resilient modulus is an indicator of a material's deflection behavior. In this research, resilient modulus at both $5^{\circ} \mathrm{C}$ and $25^{\circ} \mathrm{C}$ is correlated with $R_{100}$ (recoverable deformation of the binder) obtained from the MSCR test. Results are shown in Figure 9. The correlation between resilient modulus at both $5^{\circ} \mathrm{C}$ and $25^{\circ} \mathrm{C}$ and $R_{100}$, had a regression coefficient more than 0.97 .

\section{Conclusion}

(1) The results of the MSCR test indicate improvement of elastic properties of modified asphalt binders at a high temperature. They also show that NC not only increases rutting resistance in modified asphalt but also reduces its stress sensitivity. Results of the MSCR test are in line with the results obtained from the dynamic creep test, presenting a strong correlation between performance of the binder and mixture. Overall, it can be deduced that the binder modified by NC contributes to resistance of the asphalt mixture against permanent deformations.

(2) The LAS test results indicate a considerable increase in the fatigue life of the NC-modified asphalt binder at low strain levels. On the other hand, the fatigue life of modified asphalt binders at high strain levels is a little less than that of the unmodified binders. Furthermore, the results of the four-point bending beam test demonstrate that adding $\mathrm{NC}$ up to 8 percent by binder content could considerably improve fatigue resistance, which confirms the results of the LAS test.

(3) According to the correlation of the flow number, MQ, and $M_{r}$ with the results of the MSCR test, it could be concluded that the MSCR test results correlate very well with mixture test results related to rutting performance.

(4) According to a fairly well correlation between binder and mixture test outputs obtained in this research, it is promising to develop a phenomenological relation between characteristics of the binder and mixture using more extensive data and considering important parameters, in future research, so more time and materials are saved using binder tests instead of the mixture tests.

\section{Conflicts of Interest}

The authors declare that there are no conflicts of interest regarding the publication of this paper.

\section{References}

[1] M. Baqersad, A. Hamedi, M. Mohammadafzali, and H. Ali, "Asphalt mixture segregation detection: digital image processing approach," Advances in Materials Science and Engineering, vol. 2017, Article ID 9493408, 6 pages, 2017.

[2] C. Fang, R. Yu, S. Liu, and Y. Li, "Nanomaterials applied in asphalt modification: a review," Journal of Materials Science \& Technology, vol. 29, no. 7, pp. 589-594, 2013.

[3] A. Kavussi and P. Barghabany, "Investigating fatigue behavior of nanoclay and nano hydrated lime modified bitumen using LAS test," Journal of Materials in Civil Engineering, vol. 28, no. 3, p. 04015136, 2015.

[4] M. Van de Ven, A. Molenaar, and J. Besamusca, "Nanoclay for binder modification of asphalt mixtures," in Proceedings of the 7th International RILEM Symposium on Advanced Testing and Characterization of Bituminous Materials, Rhodes, Greece, May 2009.

[5] A. N. Amirkhanian, F. Xiao, and S. N. Amirkhanian, "Characterization of unaged asphalt binder modified with carbon nano particles," International Journal of Pavement Research and Technology, vol. 4, no. 5, pp. 281-286, 2011.

[6] H. Yao, Z. You, L. Li et al., "Properties and chemical bonding of asphalt and asphalt mixtures modified with nanosilica," Journal of Materials in Civil Engineering, vol. 25, 2012.

[7] J. A. D'Angelo, "The relationship of the MSCR test to rutting," Road Materials and Pavement Design, vol. 10, no. 1, pp. 61-80, 2009.

[8] M. Mohammadafzali, H. Ali, J. Musselman, G. Sholar, S. Kim, and T. Nash, "Long-term aging of recycled asphalt binders: 
a laboratory evaluation based on performance grade tests," in Proceedings of the Airfield and Highway Pavements 2015, pp. 617-627, Miami, FL, USA, June 2015.

[9] F. Zhou, W. Mogawer, H. Li, A. Andriescu, and A. Copeland, "Evaluation of fatigue tests for characterizing asphalt binders," Journal of Materials in Civil Engineering, vol. 25, no. 5, pp. 610-617, 2012.

[10] AASHTO-T 32, Determining the fatigue life of compacted hot mix asphalt (HMA) subjected test repeated flexural bending, American Association of State Highway \& Transportation Officials, Washington, DC, USA, 2007.

[11] ASTM D7405-10, Standard Test Method for Multiple Stress Creep and Recovery (MSCR) of Asphalt Binder Using a Dynamic Shear Rheometer, ASTM International, West Conshohocken, PA, USA, 2010.

[12] C. M. Johnson, Estimating Asphalt Binder Fatigue Resistance Using an Accelerated Test Method, University of WisconsinMadison, Madison, WI, USA, 2010.

[13] C. Hintz, Understanding Mechanisms Leading to Asphalt Binder Fatigue, University of Wisconsin-Madison, Madison, WI, USA, 2012.

[14] A. Behnood and M. Ameri, "Experimental investigation of stone matrix asphalt mixtures containing steel slag," Scientia Iranica, vol. 19, no. 5, pp. 1214-1219, 2012.

[15] ASTM D4123-82, Standard Test Method for Indirect Tension Test for Resilient Modulus of Bituminous Mixtures (Withdrawn 2003), ASTM International, West Conshohocken, PA, USA, 1995.

[16] Y. Huang, Pavement Analysis and Design, Peason Education, Inc., USA, 2004.

[17] K. E. Kaloush, M. W. Witczak, G. B. Way, A. Zborowski, M. Abojaradeh, and A. Sotil, Performance Evaluation of Arizona Asphalt Rubber Mixtures Using Advanced Dynamic Material Characterization Tests. Final Report, FNF Construction, Inc. and the Arizona Department of Transportation, Arizona State University, Tempe, AZ, USA, 2002.

[18] N. I. M. Yusoff, A. A. S. Breem, H. N. M. Alattug, A. Hamim, and J. Ahmad, "The effects of moisture susceptibility and ageing conditions on nano-silica/polymer-modified asphalt mixtures," Construction and Building Materials, vol. 72, pp. 139-147, 2014.

[19] M. Hasaninia and F. Haddadi, "The characteristics of hot mixed asphalt modified by nanosilica," Petroleum Science and Technology, vol. 35, no. 4, pp. 351-359, 2017.

[20] A. Massahi, H. Ali, F. Koohifar, and M. Mohammadafzali, "Analysis of pavement raveling using smartphone," in Transportation Research Board 95th Annual Meeting (No. 16-6155), January 2016.

[21] M. Ameri, S. Nowbakht, M. Molayem, and M. H. Mirabimoghaddam, "A study on fatigue modeling of hot mix asphalt mixtures based on the viscoelastic continuum damage properties of asphalt binder," Construction and Building Materials, vol. 106, pp. 243-252, 2016. 


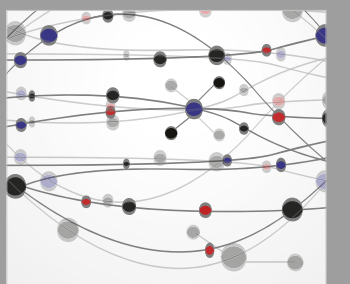

The Scientific World Journal
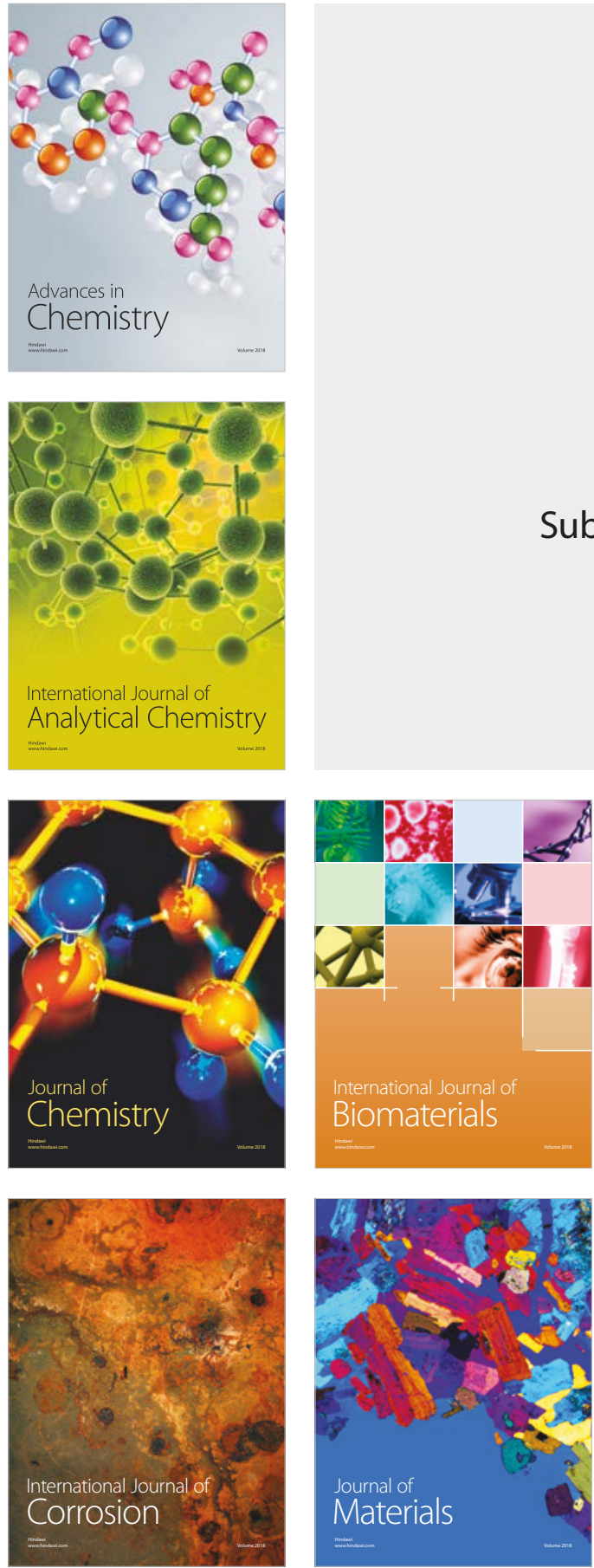

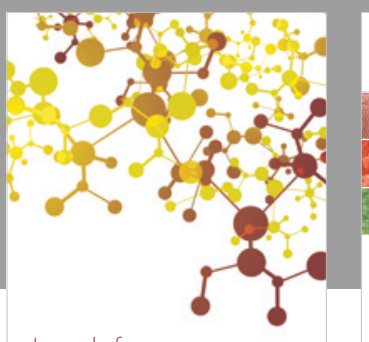

Journal of

Applied Chemistry
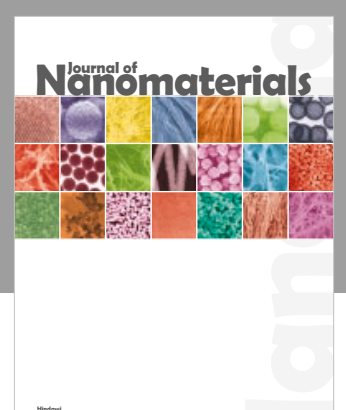

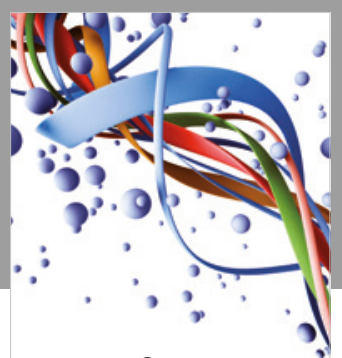

Scientifica

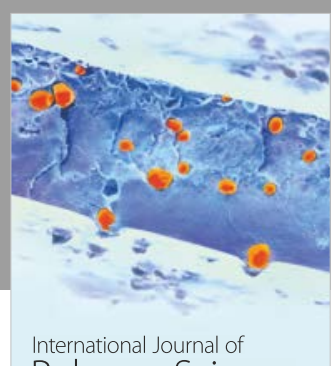

Polymer Science

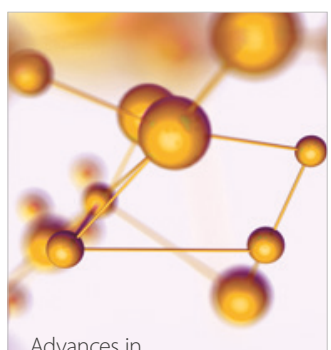

Physical Chemistry
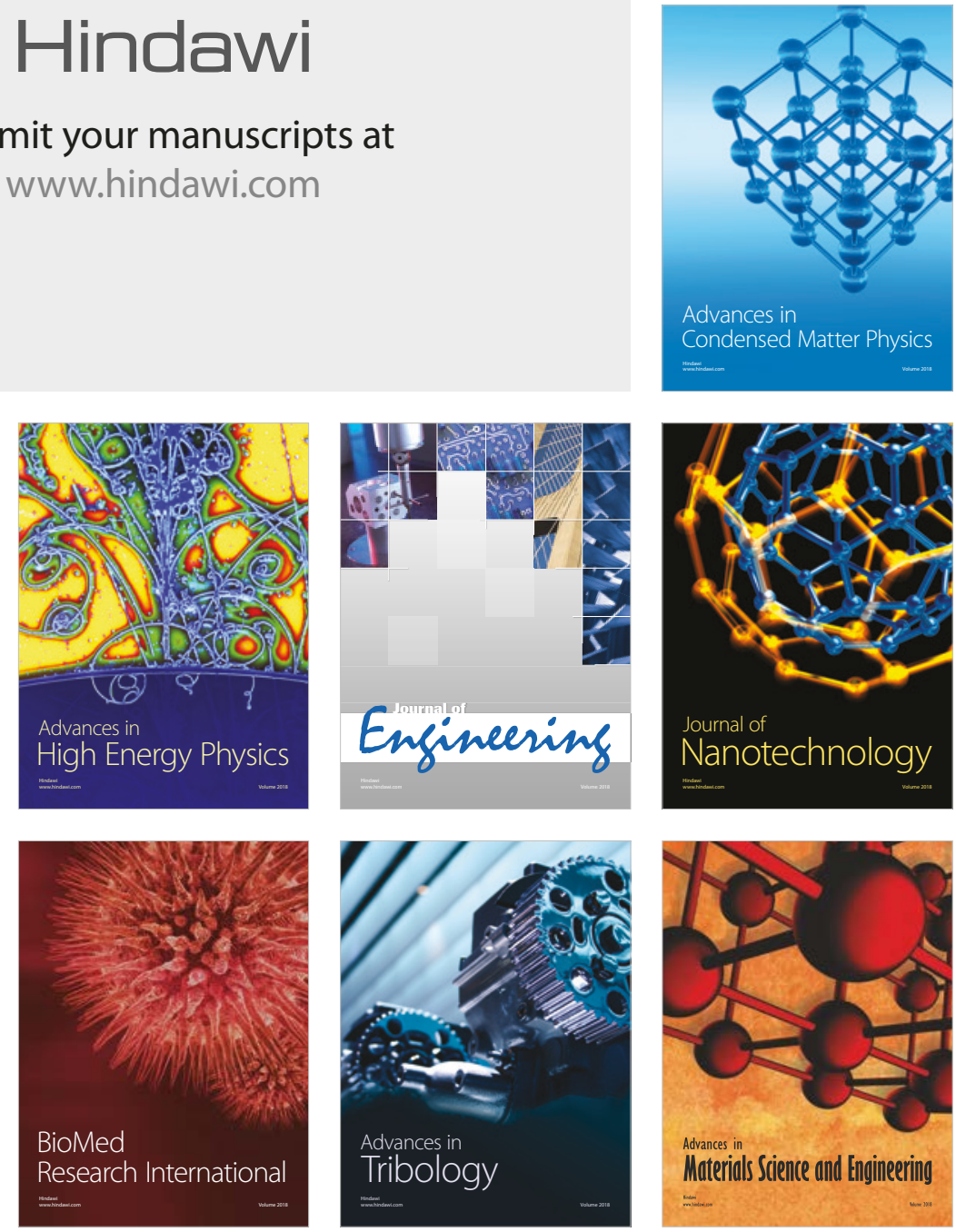